\title{
Predicting critical thresholds of aquaculture waste loading to coastal sediment
}

\author{
D.W. Paraska a ${ }^{\text {L.C. Bruce }}{ }^{\text {a }}$, G. Shiell ${ }^{\text {b }}$ and M.R. Hipsey ${ }^{a}$ \\ a Aquatic Ecodynamics, School of Earth and Environment, The University of Western Australia, \\ Perth, Australia \\ ${ }^{b}$ BMT Oceanica, Wembley, Australia \\ Email: louise.bruce@uwa.edu.au
}

\begin{abstract}
The use of cages in the ocean to support finfish aquaculture is increasing as an important food supply industry. However, local environmental impacts directly below and around cages can include the degradation of water and sediment quality. In particular, high rates of organic matter deposition to the sea floor beneath the cage, primarily from the deposition of faeces and uneaten food, drives dissolved oxygen consumption and hydrogen sulfide production, ultimately leaving the sediment environment uninhabitable for benthic macrofauna.

The aim of this study was to develop and apply a vertically-resolved sediment biogeochemical model (Figure 1) to simulate the response of marine sediment to organic matter loading from fish cages. After an initial spin-up period, the model simulations assume aquaculture operations for a five year period, followed by seven years of recovery. The model is run within a Monte Carlo framework to assess sensitivity to key parameters. A series of simulations were then undertaken to define how changes in the extent of loading impact upon sediment chemical concentration profiles and sediment-water fluxes of variables such as oxygen, nutrients and sulfide. We then defined threshold-loading rates, based on sulfide accumulation in the surficial sediment, that correspond to a low, medium or large impact to sediment quality.

The recovery time for sediment experiencing five years of fish-waste input is then computed, with an associated range of uncertainty. Recovery time is defined as the time taken from the end of aquaculture operations to the time when oxygen in the surficial sediment recovers to $85 \%$ of its base concentration. For each rate of loading, we categorize whether the top $5 \mathrm{~cm}$ of sediment would recover in less than 1 year, between 1 and 5 years, or $>5$ years.

The results of the analysis may be interpreted by managers and operators to assess the likelihood of sediment condition, and the potential for recovery once farming has ceased, for a range of stocking densities. Further the model approach may be applied in conjunction with hydrodynamic model assessments of waste dispersion and deposition to assess the potential footprint of cage installations.
\end{abstract}

Keywords: Sediment biogeochemical model, early diagenesis, coastal sediment quality, fish cages, environmental impact thresholds 


\section{INTRODUCTION}

Finfish aquaculture is an increasingly important contributor to the global food supply (Tacon and Metian 2013). However, the challenge for regulatory agencies is that the intensive nature of aquaculture cages leads to local environmental impacts, including degradation of water and sediment quality. The high concentration of fish in the cages is known to create a high rate of organic matter deposition to the sea floor beneath the cage, primarily from the deposition of faeces and uneaten food. The organic matter drives the metabolism of sediment bacteria and triggers a series of chemical reactions that cause deterioration of the health of the sediment environment. In particular, accumulation of high concentrations of labile organic matter drive dissolved oxygen consumption and excessive hydrogen sulfide production, ultimately leaving the sediment environment uninhabitable for benthic infauna (Hargrave et al. 2008) (Figure 1).

For successful planning and management of cage installations it is therefore essential to identify the critical amounts of organic matter deposition, and therefore stocking densities, that lead to sulfidic conditions and the unacceptable loss of benthic infauna. However, there is no simple relationship between organic matter influx and the resulting sediment chemical concentrations that can be applied to all environments. Hargrave et al. (2008) provide a synthesis of a diversity of empirical studies, however, measurements of the sediment are difficult to obtain because of the fine spatial and temporal scale needed to be measured below the sea surface. Other studies summarising sediment quality impacts from finfish aquaculture have been reported by Macleod and Forbes (2004), Tanner et al. (2007) and Volkman et al. (2009).

There are limited publications describing the use of modelling tools for assessment of aquaculture impacts to sediment. The main study is the application of a vertically-resolved sediment diagenesis model by Brigolin et al. (2009) to assess the impacts of various magnitudes of fish waste deposition on sediment chemical concentrations. In this analysis, we apply a similar sediment diagenesis model to quantify changes in sediment conditions, in response to a spectrum of different rates of organic matter loading from fish cages. Specifically, the aims of this study were to:

- quantify the extent of changes in sediment chemical concentrations and dissolved fluxes at the sediment water interface during aquaculture operations,

- predict the time needed for the sediment chemical concentrations to return to pre-fish farming conditions, and

- identify indicative thresholds of organic matter loading above which the loss of benthic integrity is likely to occur.

The approach taken was firstly to develop a comprehensive sediment diagenesis model able to predict the physical, chemical and biological processes within the sediment. The model is applied to "typical"

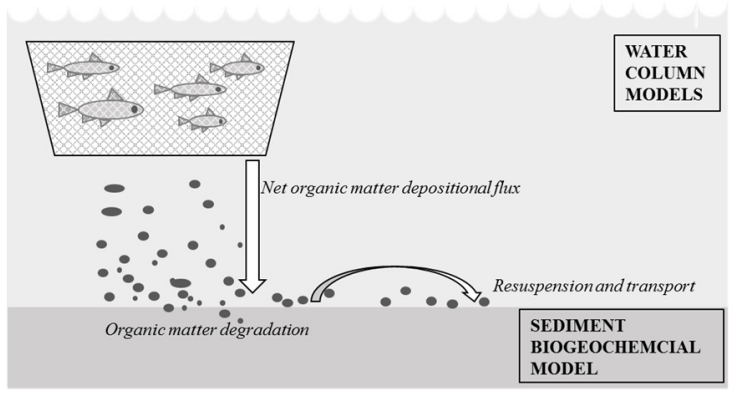

Figure 1. Schematic of cage impacts on underlying sediment. Fish waste is simulated as organic matter deposition as a boundary condition to the sediment biogeochemistry model. coastal sediment, firstly under background conditions, then with five years of organic matter deposition, then seven years with no deposition when the sediment was able to recover. The simulation setup was idealised but with typical total organic carbon (TOC), total nitrogen (TN) and total phosphorus (TP) concentrations. The resulting chemical concentrations were then assessed against a spectrum of organic matter deposition fluxes, from $1 \times 10^{2}$ to $5 \times 10^{6} \mathrm{mmol} \mathrm{m}^{-2} \mathrm{y}^{-1}$ and used to explore how the sediment would respond to a wide range of stocking densities, near and far from the cages. The time for recovery of sediment oxygen concentrations to nearly pre-farming levels, and the changes in absolute sulfide concentrations, were assessed and used to define thresholds for classifying the impacts of aquaculture on the sediment and targets for ecological protection.

\section{MODELLING SEDIMENT QUALITY}

\subsection{Sediment Model: CANDI-AED}

Sediment biogeochemical models that simulate the transport and reaction calculations required to determine sediment conditions and predict the sediment oxygen and nutrient fluxes for associated water column models are widely used for sediment assessment across a range of marine and coastal environments (see Paraska et al., 2014, for a detailed review). CANDI-AED, the sediment model code developed for this study incorporates the 
original CANDI model created by Boudreau (1996) extended to include the organic matter dynamics and geochemical modules of the AED2 model (Hipsey et al. 2013).

The diagenesis model solves reaction and transport of numerous particulate and dissolved chemicals numerically over spatial and temporal steps. It is common to assume that vertical gradients in chemical concentration dominate over horizontal gradients, and therefore the model is resolved with layers of depth, the thickness of which increase exponentially from $\mathrm{mm}$ at the surface to $\mathrm{cm}$ in the deepest layers. The transport reactions are considered only as vertical diffusion and advection, where advection is the progress of each layer downwards relative to the sediment-water interface, caused by deposition. Diffusion is a result of chemical diffusion due to chemical

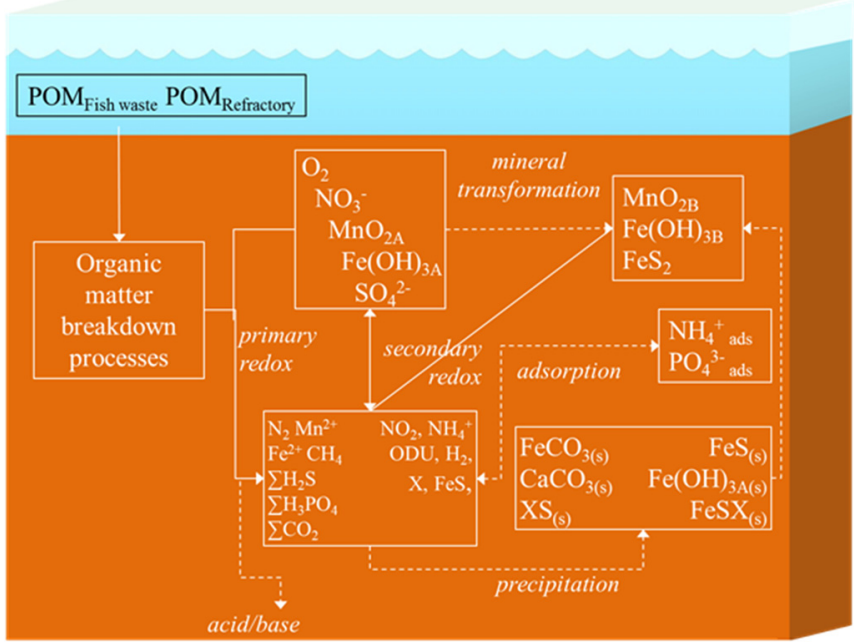

Figure 2. Schematic of CANDI-AED sediment early diagenesis model including chemical processes of organic matter transformation and oxidation, and reduction/oxidation, crystallisation, adsorption and precipitation reactions of inorganic by-products. concentration gradients for solutes, and bioturbation in the upper layers of sediment where benthic infauna mix the sediment for both solutes and solids.

The chemical reactions can be broadly defined as primary and secondary reactions, summarised in Figure 2. Primary reactions are the microbially-driven breakdown reactions of organic matter via a series of six redox pathways. These pathways include the microbially-driven edox reactions of organic matter using $\mathrm{O} 2, \mathrm{NO} 3-, \quad \mathrm{MnO} 2$, $\mathrm{Fe}(\mathrm{OH}) 3$, SO42- and methanogenesis. These reactions are the driving force of most of the other chemical reactions that take place in the sediment, and in this context, a large deposition of fish food and faecal matter serve to shift chemical concentrations away

Table 1. Summary of assigned model parameters and their description.

\begin{tabular}{|c|c|c|c|}
\hline ParameterDescription & Range & $\begin{array}{l}\text { Default } \\
\text { value }\end{array}$ & Units \\
\hline Surface biodiffusion coefficient & 0 to 40 & 20 & $\mathrm{~cm}^{2} \mathrm{y}^{-1}$ \\
\hline Half depth for Gaussian distribution of bioturbation & 0 to 5 & 40 & $\mathrm{~cm}$ \\
\hline Sediment particle burial velocity & 0.05 to 5 & 0.2 & $\mathrm{~cm} \mathrm{y}^{-1}$ \\
\hline Porosity at the sediment-water interface & 0.7 to 0.99 & 0.9 & $\mathrm{~cm}^{3} \mathrm{~cm}^{-3}$ \\
\hline Porosity at depth & 0.0 to 0.1 & 0.07 & $\mathrm{~cm}^{3} \mathrm{~cm}^{-3}$ \\
\hline Maximum irrigation depth & 0 to 5 & 0.28 & $\mathrm{~cm}$ \\
\hline Kinetic oxidation constant of fish-derived organic matter & 1 to 50 & 1.0 & $y^{-1}$ \\
\hline Kinetic oxidation constant of refractory organic matter & 0.005 & - & $y^{-1}$ \\
\hline Kinetic oxidation constant for $\mathrm{NH}_{4}{ }^{+}$by $\mathrm{O}_{2}$ & 900 to 2000 & 1500 & $\mathrm{y}^{-1}$ \\
\hline Kinetic oxidation constant for $\mathrm{H}_{2} \mathrm{~S}$ by $\mathrm{O}_{2}$ & 1 to 1000 & 160 & $\mathrm{y}^{-1}$ \\
\hline Kinetic constant for oxidation of $\mathrm{Mn}^{2+}$ by $\mathrm{O}_{2}$ & 0.0 & - & $y^{-1}$ \\
\hline Kinetic constant for oxidation of $\mathrm{Fe}^{2+}$ by $\mathrm{O}_{2}$ & $1.45 \times 10^{5}$ & - & $y^{-1}$ \\
\hline Kinetic constant for oxidation of $\mathrm{CH}_{4}$ by $\mathrm{O}_{2}$ & $1 \times 10^{7}$ & & $\mathrm{y}^{-1}$ \\
\hline Kinetic constant for oxidation of $\mathrm{FeS}$ by $\mathrm{O}_{2}$ & 320 & & $y^{-1}$ \\
\hline Kinetic constant for oxidation of $\mathrm{Fe}^{2+}$ by $\mathrm{NO}_{3}^{-}$ & 0.0 & & $\mathrm{y}^{-1}$ \\
\hline Kinetic constant for oxidation of $\mathrm{HS}^{-}$by $\mathrm{NO}_{3}{ }^{-}$ & 0.0 & & $y^{-1}$ \\
\hline Kinetic constant for oxidation of $\mathrm{Fe}^{2+}$ by $\mathrm{MnO}_{2}$ & 3000 & & $\mathrm{y}^{-1}$ \\
\hline Kinetic constant for oxidation of $\mathrm{FeS}_{2}$ by $\mathrm{MnO}_{2}$ & 20 & & $\mathrm{y}^{-1}$ \\
\hline Kinetic constant for oxidation of $\mathrm{FeS}$ by $\mathrm{MnO}_{2}$ & 0.0 & & $y^{-1}$ \\
\hline Kinetic constant for oxidation of $\mathrm{HS}^{-}$by $\mathrm{Fe}(\mathrm{OH})_{3}$ & 8.0 & & $\mathrm{y}^{-1}$ \\
\hline Kinetic constant for oxidation of $\mathrm{FeS}$ by $\mathrm{Fe}(\mathrm{OH})_{3}$ & 0.0 & & $\mathrm{y}^{-1}$ \\
\hline Kinetic constant for oxidation of $\mathrm{CH}_{4}$ by $\mathrm{SO}_{4}{ }^{2-}$ & 10.0 & & $y^{-1}$ \\
\hline Kinetic constant for precipitation of FeS & 0.15 & & $y^{-1}$ \\
\hline Kinetic constant for precipitation of $\mathrm{FeCO}_{3}$ & 0.25 & & $y^{-1}$ \\
\hline Kinetic constant for precipitation of $\mathrm{CaCO}_{3}$ & 0.0 & & $y^{-1}$ \\
\hline Monod constant for $\mathrm{O}_{2}$ limitation & 0.02 & & $\mathrm{mmol} \mathrm{L}^{-1}$ \\
\hline Monod constant for $\mathrm{NO}_{3}^{-}$limitation & 0.005 & & $\mathrm{mmol} \mathrm{L}^{-1}$ \\
\hline Monod constant for $\mathrm{MnO}_{2}$ limitation & 16 & & $\mathrm{mmol} \mathrm{L}-1$ \\
\hline Monod constant for $\mathrm{Fe}(\mathrm{OH})_{3}$ limitation & 100 & & $\mathrm{mmol} \mathrm{L}^{-1}$ \\
\hline Monod constant for $\mathrm{SO}_{4}{ }^{2-}$ limitation & 1600 & & $\mathrm{mmol} \mathrm{L}^{-1}$ \\
\hline
\end{tabular}


from the natural equilibrium that occurs in oligotrophic marine waters. Secondary reactions are the redox reactions of the by-products of primary reactions, such as reduced iron and $\mathrm{H}_{2} \mathrm{~S}$, as well as acid-base reactions, precipitation-dissolution reactions and adsorption-desorption reactions.

\subsection{Model Setup and Parameter Selection}

To demonstrate the CANDI-AED model was accurately capturing sediment physical and biogeochemical processes, a benchmark simulation was undertaken comparing the model against the commonly used ocean sediment biogeochemical model by Van Capellan and Wang (1996). The model domain was then configured to be representative of a typical coastal sediment, using a vertical grid of 50 layers, with variable depth providing increased resolution near the surface, and parameters as outlined in in Table 1. Simulations were run for 17 years, including a 5 year spin-up period of no aquaculture, 5 years of aquaculture waste input, and then 7 years for recovery.

\subsection{Defining Fish Cage Outputs and Deposition Flux}

The deposition of particulate organic matter derived from waste fish food and fish faeces varies depending on the stocking density of the cages, and the level of advection and dispersion of particles that occur from the base of the cage to the seabed. Rather than predicting any specific case, this assessment ran the model over a wide range of deposition fluxes to generate a continuous relationship between flux and sediment response. Ten different deposition scenarios were assessed, each scenario corresponding to a different flux of organic carbon derived from fish farm waste (ranging from: $10^{2}$ to $10^{6} \mathrm{mmol} \mathrm{m}^{-2} \mathrm{y}^{-1}$ ).

\subsection{Stochastic Approach for Assessing Threshold Uncertainty}

To demonstrate the sensitivity of the model predictions within the range of parameter uncertainty, simulations were run with a basic setup and default parameters as described above. For each fish waste deposition flux, 40 repeated simulations were then run using randomly-generated within range values for the key uncertain parameters listed in Table 1. The results were then compiled and the median value was calculated, along with the $5,10,25,75,90$ and $95^{\text {th }}$ percentile results. These were used to explore the sensitivity of concentration variability of depth (Section 3), in addition to the recovery time of the sediment after the end of aquaculture (Section 4).

\section{3.}
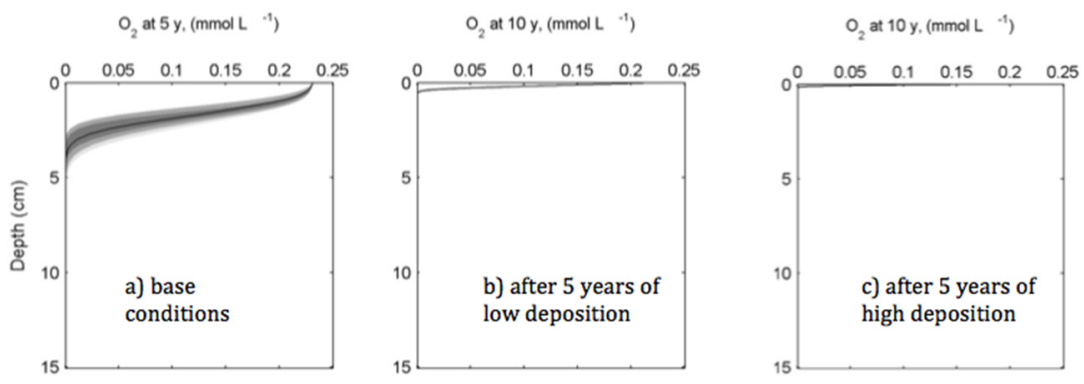

A comparison of the pre and post aquaculture chemical profiles is shown in Figure 3. The transition from welloxygenated (up to $5 \mathrm{~cm}$ oxygen penetration depth, (Figure 3a) to anoxic occurs for relatively low deposition rates (Figure 3b), with entirely anaerobic conditions occurring at high flux
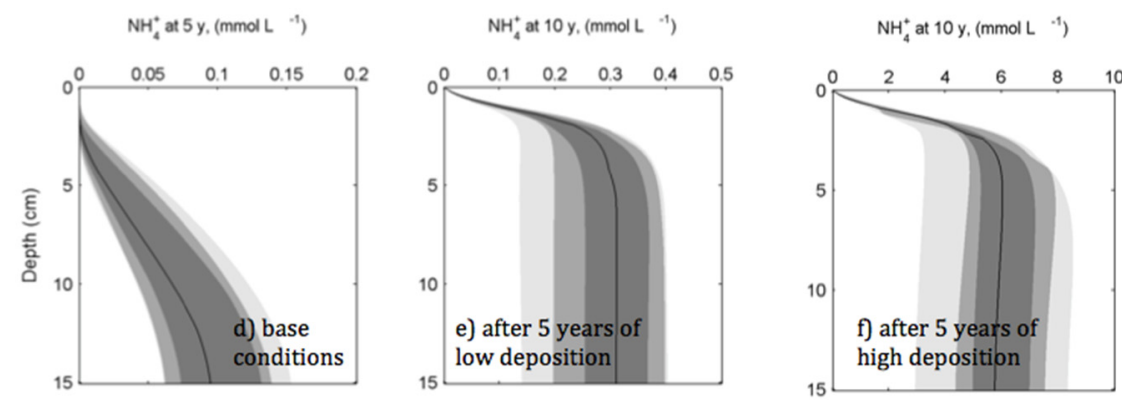

Figure 3. Concentration profiles of $\mathrm{O}_{2}$ and $\mathrm{NH}_{4}{ }^{+}$under base conditions (left), a low fish-waste deposition rate (middle; $5 \times 10^{3} \mathrm{mmol} \mathrm{C} \mathrm{m}^{-2} \mathrm{y}^{-1}$ ) and a high fishwaste deposition rate (right; $1 \times 10^{5} \mathrm{mmol} \mathrm{C} \mathrm{m}^{-2} \mathrm{y}^{-1}$ ).

densities (Figure 3c),

and this is reflected also in the build up of $\mathrm{NH}_{4}^{+}$, and other constituents such as sulfide (not shown). Figure 4 showing model output generated by applying the default values of uncertain parameters, demonstrates the changes that occur during and following the high rate of fish-waste deposition. Once input ceases, the fish waste organic matter in the sediments is rapidly consumed by bacteria leading to a rapid drop in concentration. 


\section{ASSIGNING SEDIMENT CONDITION THRESHOLDS FOR MANAGEMENT}

The previous section demonstrated sediment conditions for several chosen fish waste deposition rates. Here

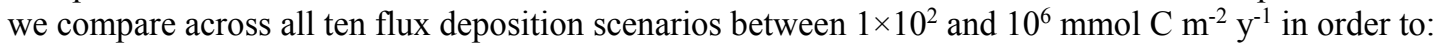

- identify the relationship between the fish-waste deposition flux and the associated response in sediment chemical fluxes back to the water column,

- link fish waste deposition flux to expected surficial sediment concentrations of key sediment condition attributes relevant to management triggers,

- identify the level of fish waste deposition that is likely to lead to toxic conditions for the benthic fauna community during aquaculture, and

- identify the recovery time of sediment after aquaculture ceases.

\subsection{Changes to the}

\section{Sediment-Water Interface}

\section{Chemical Fluxes}

Fluxes of dissolved variables across the sediment-water interface were compared across the 10 different deposition loading scenarios simulated using default parameter values, before, during and after aquaculture (Figure 5). The $\mathrm{O}_{2}$ flux returned to its pre-farming flux within 5 years for fish waste depositions between $10^{2}$ and $10^{5} \mathrm{mmol} \mathrm{C} \mathrm{m} \mathrm{C}^{-1}$. $\mathrm{NH}_{4}{ }^{+}$and $\mathrm{PO}_{4}{ }^{3-}$ returned to their near-zero fluxes after five years despite very large increases at high deposition rates. $\mathrm{NO}_{3}{ }^{-}$displayed a more complex pattern; with fish waste deposition between $10^{2}$ and $10^{6} \mathrm{mmol} \mathrm{C} \mathrm{m}^{-2} \mathrm{y}^{-1}$ during aquaculture, there was a net production of $\mathrm{NO}_{3}{ }^{-}$, from the nitrification of organic $\mathrm{N}$; for fish wastes above $10^{6} \mathrm{mmol} \mathrm{C}$ $\mathrm{m}^{-2} \mathrm{y}^{-1}, \mathrm{O}_{2}$ was consumed and there was a net consumption of $\mathrm{NO}_{3}{ }^{-}$due to denitrification.
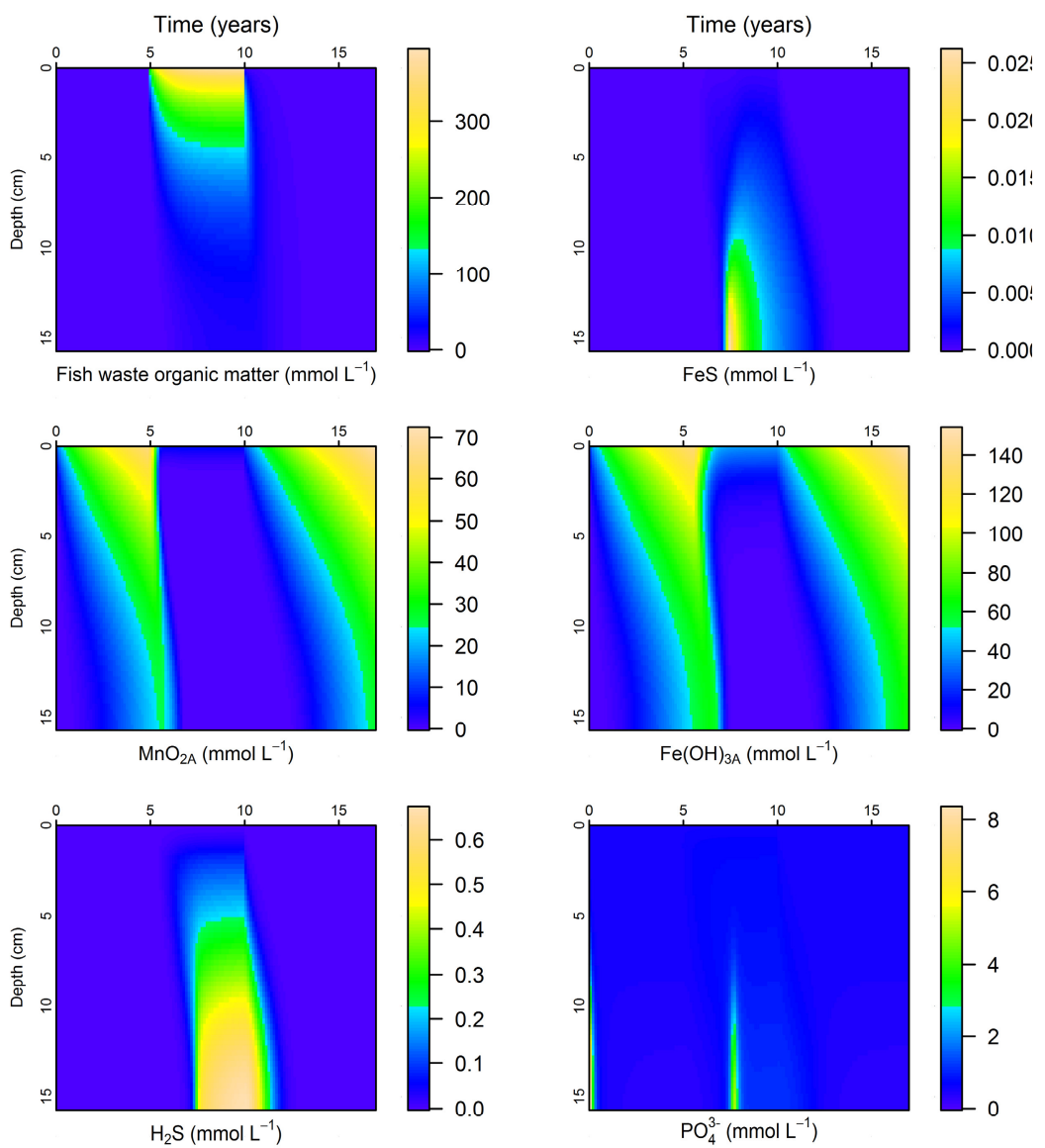

Figure 4. Evolution of concentration of key sediment attributes before, during and after deposition.

Table 2. Ecological protection categories based on Hargrave et al. (2008) and Macleod and Forbes (2004).

\begin{tabular}{llcc} 
Ecological protection & $\mathrm{O}_{2}$ concentration & $\begin{array}{c}\mathrm{H}_{2} \mathrm{~S} \text { concentration } \\
(0 \text { to } 2 \mathrm{~cm})\end{array}$ & $\begin{array}{c}\text { Macrofauna abundance } \\
\text { and diversity }\end{array}$ \\
High & Oxic & $<100 \mu \mathrm{M}$ & $\begin{array}{c}\text { Not affected } \\
\text { Medium }\end{array}$ \\
Low $>50 \%$ & Mild hypoxic stress & $<300 \mu \mathrm{M}$ & $<50 \%$ reduction of abundance \\
Low $>85 \%$ & Hypoxic stress & $<6000 \mu \mathrm{M}$ & $<50 \%$ reduction of abundance \\
\hline
\end{tabular}




\subsection{Response of Surficial Sediment Concentrations to Fish Waste Accumulation}

As in the previous section the model simulations were used to derive a relationship between deposition rate and mean concentration of all dissolved and particulate values during aquaculture operation (not shown, but results used for Table 3 ).

\subsection{Flux Thresholds Where Conditions Become Damaging to Benthic Fauna}

Damage to the sediment environment for benthic fauna from fish farming may be assessed based on the depth of anoxia, and by the concentration of $\mathrm{H}_{2} \mathrm{~S}$. The nomogram presented by Hargrave et al., (2008) and the categories of Macleod and Forbes (2004) were used to connect the concentrations of $\mathrm{O}_{2}$ and $\mathrm{H}_{2} \mathrm{~S}$ and the likely effects for benthic fauna, and then to define four categories for ecological protection (Table 2).

\subsection{Defining the Recovery Time of Sediment Post-Cage Operation}
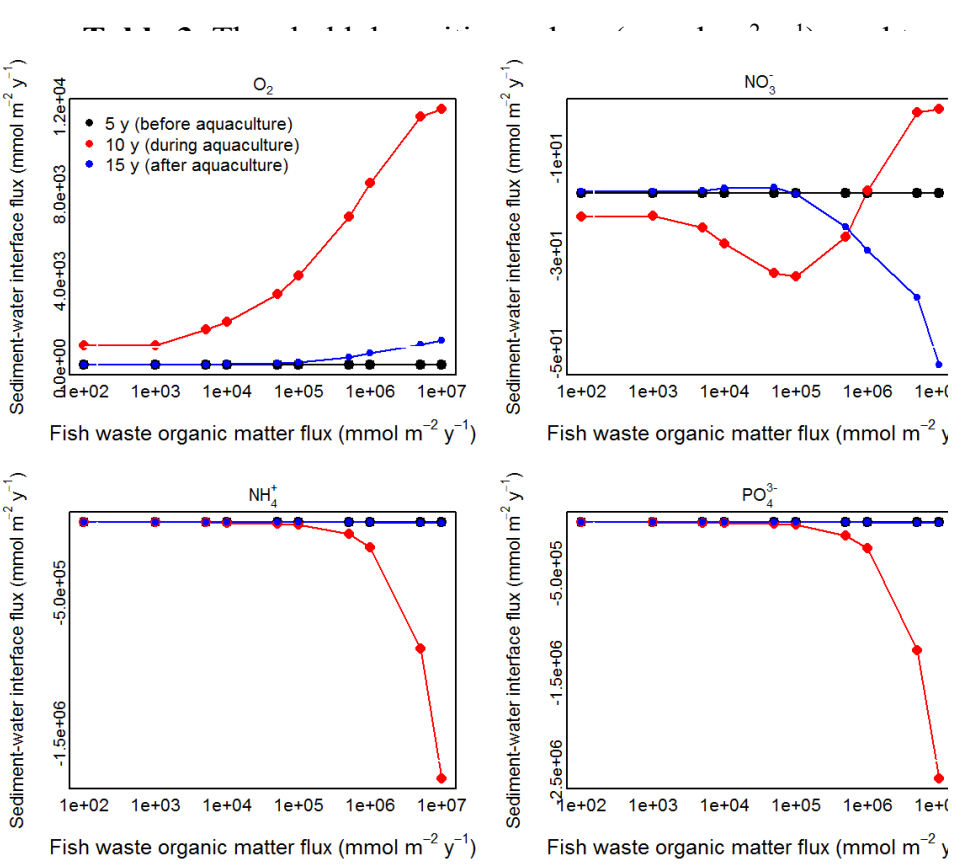

Fish waste organic matter flux $(\mathrm{mmol} \mathrm{m})^{-2}$

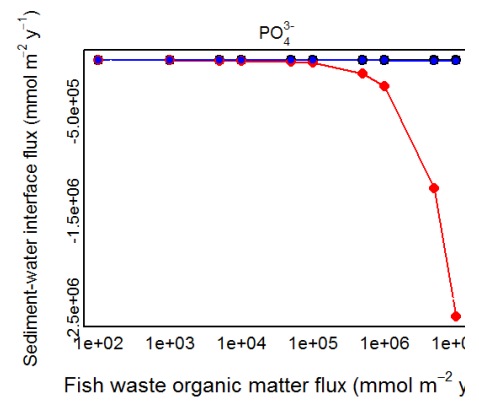

Figure 5. Fluxes of solutes across the sediment water interface $\left(\mathrm{mmol} \mathrm{m} \mathrm{m}^{-2} \mathrm{y}^{-1}\right)$, as a function of fish farm organic matter deposition.

Positive numbers on the $y$ axes indicate a flux from the water column into the sediment, or a demand by the sediment. Negative numbers indicate a flux from the sediment to the water column, thus, production in the sediment.

The time for recovery of sediment once farming has ceased is an important consideration in determining management options and regulatory approvals. The model was used to forecast the recovery time, by assessing when concentrations of key variables $\left(\mathrm{O}_{2}, \mathrm{~S}^{2-}, \mathrm{NH}_{4}{ }^{+}\right.$etc.) within the top $5 \mathrm{~cm}$ of sediment returned to prefarming conditions. To demonstrate the utility of the model for this purpose the time at which the concentration of $\mathrm{O}_{2}$ returned to within $85 \%$ of its pre-farming state is shown here (Figure 6).

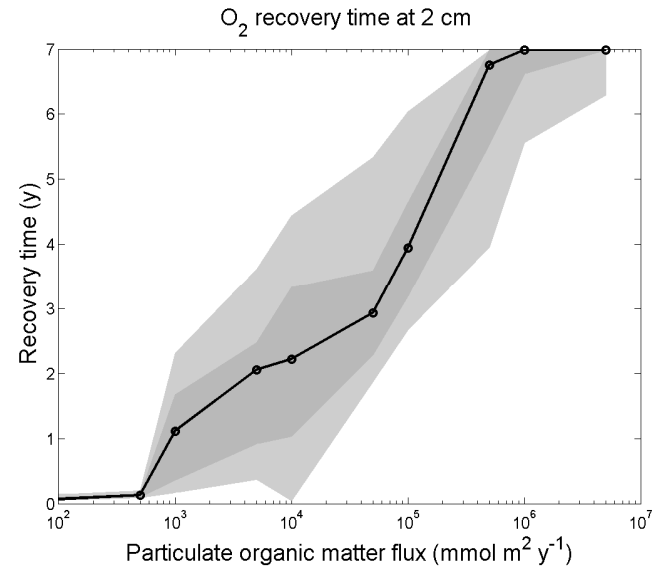

Figure 6. Recovery times for $\mathrm{O}_{2}$ at $2 \mathrm{~cm}$. The $\mathrm{x}$ axis is the fish waste deposition flux for each of the simulations $\left(\mathrm{mmol} \mathrm{C} \mathrm{m} \mathrm{y}^{-2} \mathrm{y}^{-1}\right)$. The $\mathrm{y}$ axis is the time at which the concentration reaches $85 \%$ of the maximum $\mathrm{O}_{2}$ concentration reached before the start of aquaculture.
In order to identify critical deposition rates, the recovery time was then classified as:

- $\underline{\text { High }}(\mathrm{HI})$ : Sediment is considered to be highly impacted when the sediment conditions do not return to their original condition within 5 years. In this case the effects on benthic organisms are predicted to be irreversible over this period.

- Moderate (MI): Sediment is considered to be moderately impacted when the sediment condition is impacted during aquaculture operation, but can recover within 1 to 5 years.

- Influenced (In): In this category the sediment concentrations are affected but the surficial sediment concentrations would return to a preaquaculture state in less than 1 year after aquaculture ceases.

Table 3 summarises critical deposition fluxes associated with the above three recovery categories simulated using default parameter values. 
Paraska et al., Critical thresholds of aquaculture waste inputs to coastal sediment

\section{CONCLUSIONS}

This analysis has applied a sediment diagenesis model able to resolve the sharp vertical gradients near the sediment-water interface to assess the change in sediment geochemical conditions for a range of fish-waste loading scenarios. The model approach described in this study may be used as a to guide to determine the potential stocking densities of fish cages by establishing the relationship between organic matter loading and thresholds related to sediment quality and recovery. In addition, the results may be used in conjunction with hydrodynamic-water quality models able to predict the spatial distribution of particulate waste deposition around cage clusters.

\section{REFERENCES}

Berner, R. (1980). Early diagenesis: A theoretical approach. New Jersey, Princeton University Press.

Boudreau, B.P. (1996). A method-of-lines code for carbon and nutrient diagenesis in aquatic sediments. Computers and Geosciences, 22, 479-496.

Brigolin, D., R. Pastres, T.D. Nickell, C.J. Cromey, D.R. Aguilera, and P. Regnier (2009). Modelling the impact of aquaculture on early diagenetic processes in sea loch sediments. Marine Ecology-Progress Series, 388, 63-80.

Hargrave, B.T., M. Holmer, and C.P. Newcombe (2008). Towards a classification of organic enrichment in marine sediments based on biogeochemical indicators. Marine Pollution Bulletin, 56, 810-824.

Hipsey, M.R., L.C. Bruce, and D.H. Hamilton (2013). Aquatic Ecodynamics (AED) Model Library Science Manual, available at: http://aed.see.uwa.edu.au/research/models/AED/Download/AED_ScienceManual_v4_draft.pdf

Macleod, C., and S. Forbes (2004). Guide to the assessment of sediment condition at marine finfish farms in Tasmania. Tasmanian Aquaculture and Fisheries Institute, University of Tasmania

Paraska, D.W., M.R. Hipsey, and S.U. Salmon (2014). Sediment diagenesis models: Review of approaches, challenges and opportunities. Environmental Modelling and Software, 61, 297-325.

Tacon, A.G.J., and M. Metian (2013). Fish matters: Importance of aquatic foods in human nutrition and global food supply. Reviews in Fisheries Science, 21, 22-38.

Tanner, J.E., T.D. Clark, M. Fernandez, and Q. Fitzgibbon (2007). Innovative solutions for aquaculture: spatial impacts and carrying capacity - further developing, refining and validating existing models of environmental effects of finfish farming. South Australian Research and Development Institute - Aquatic Sciences, Adelaide, Australia.

Van Cappellen, P., and Y.F. Wang (1996). Cycling of iron and manganese in surface sediments: A general theory for the coupled transport and reaction of carbon, oxygen, nitrogen, sulfur, iron, and manganese. American Journal of Science, 296, 197-243.

Volkman, J.K., P.A. Thompson, M. Herzfeld, K. Wild-Allen, S. Blackburn, C. Macleod, et al. (2009). A wholeof-ecosystem assessment of environmental issues for salmonid aquaculture, Technical Report for the Aquafin CRC, CSIRO Marine and Atmospheric Research. 